\title{
Keeping the ageing brain wired: a role for purine signalling in regulating cellular metabolism in oligodendrocyte progenitors
}

\author{
Andrea D. Rivera $^{1,2} \cdot$ Irene Chacon-De-La-Rocha ${ }^{1} \cdot$ Francesca Pieropan ${ }^{1} \cdot$ Maria Papanikolau $^{1} \cdot$ Kasum Azim $^{3}$. \\ Arthur M. Butt ${ }^{1}$ (D)
}

Received: 23 November 2020 / Revised: 4 February 2021 / Accepted: 19 February 2021 / Published online: 13 March 2021

(C) The Author(s) 2021

\begin{abstract}
White matter (WM) is a highly prominent feature in the human cerebrum and is comprised of bundles of myelinated axons that form the connectome of the brain. Myelin is formed by oligodendrocytes and is essential for rapid neuronal electrical communication that underlies the massive computing power of the human brain. Oligodendrocytes are generated throughout life by oligodendrocyte precursor cells (OPCs), which are identified by expression of the chondroitin sulphate proteoglycan NG2 (Cspg4), and are often termed NG2-glia. Adult NG2+ OPCs are slowly proliferating cells that have the stem cell-like property of self-renewal and differentiation into a pool of 'late OPCs' or 'differentiation committed' OPCs(COPs) identified by specific expression of the G-protein-coupled receptor GPR17, which are capable of differentiation into myelinating oligodendrocytes. In the adult brain, these reservoirs of OPCs and COPs ensure rapid myelination of new neuronal connections formed in response to neuronal signalling, which underpins learning and cognitive function. However, there is an age-related decline in myelination that is associated with a loss of neuronal function and cognitive decline. The underlying causes of myelin loss in ageing are manifold, but a key factor is the decay in OPC 'stemness' and a decline in their replenishment of COPs, which results in the ultimate failure of myelin regeneration. These changes in ageing OPCs are underpinned by dysregulation of neuronal signalling and OPC metabolic function. Here, we highlight the role of purine signalling in regulating OPC self-renewal and the potential importance of GPR17 and the P2X7 receptor subtype in age-related changes in OPC metabolism. Moreover, age is the main factor in the failure of myelination in chronic multiple sclerosis and myelin loss in Alzheimer's disease, hence understanding the importance of purine signalling in OPC regeneration and myelination is critical for developing new strategies for promoting repair in age-dependent neuropathology.
\end{abstract}

Keywords White matter · Oligodendrocyte · Oligodendrocyte precursor cell • OPC · NG2 · GPR17 · ATP · UDP · P2X7R · Metabolism $\cdot$ Myelin $\cdot$ Axon

This article is part of the special issue on ageing Brain in Pflügers Archiv-European Journal of Physiology

Arthur M. Butt

Arthur.butt@port.ac.uk

1 School of Pharmacy and Biomedical Science, University of Portsmouth, Portsmouth, UK

2 Department of Neuroscience, Institute of Human Anatomy, University of Padua, Padua, Italy

3 Department of Neurology, Neuroregeneration, Medical Faculty, Heinrich-Heine-University, Düsseldorf, Germany

\section{Introduction}

White matter (WM) is a prominent feature of the human cerebral hemispheres and comprises bundles of myelinated axons that form the connectome of the brain (Fig. 1). Myelin is produced by oligodendrocytes and is essential for superfast communication throughout the CNS, which underlies the massive computing power of the human brain [9]. The largest WM tract in the brain is the corpus callosum, which is responsible for interhemispheric communication and enables higherorder functions of the cerebral cortex, including intellectual processing and behaviour [21]. Cortical function areas, such as those for language and speech, are not symmetrically represented in the two hemispheres and damage to the corpus callosum results in disconnection of the cerebral hemispheres, 
Fig. 1 White matter is a prominent feature of human cerebral hemispheres. The white matter contains bundles of myelinated axons that interconnect neurons located in the widely dispersed grey matter areas. The corpus callosum is the largest white matter tract in the brain and interconnects the two cerebral hemispheres, shown in black in sagittal, dorsal and coronal views. Adapted from [58] and [21]

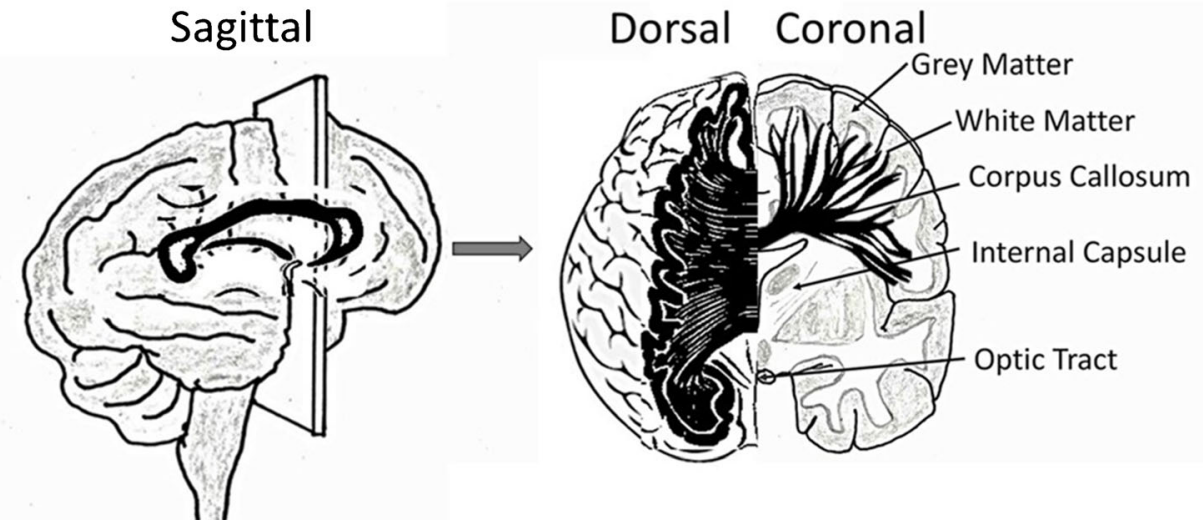

or 'split brain', when each hemisphere has separate perception, concepts and impulses to act [32]. During ageing, there is a gradual shrinkage of cerebral WM and loss of myelin, which are key factors in cognitive decline [6]. These ageing changes are accelerated in Alzheimer's disease (AD) [55], and underlie the reduced capacity for remyelination and repair in chronic MS [67]. Furthermore, defects in callosal myelination are also features of neuropsychological disorders, including bipolar disorder, schizophrenia and autism [42]. The life-long generation of oligodendrocytes is the function of adult oligodendrocyte progenitor cells (OPCs) that are identified by expression of platelet-derived growth factor-alpha receptor (PDGFR $\alpha$ ) and the NG2 chondroitin sulphate proteoglycan (CSPG4)
(Fig. 2) [64, 81]. Significantly, myelin loss in the ageing brain is associated with diminished regenerative function of OPCs, which is the focus of this review.

\section{Myelination is regulated by neuronal activity and is disrupted in ageing WM}

In the corpus callosum, myelination commences postnatally and is more or less complete by 10 years of age in humans (Krupa and Bekiesinska-Figatowska, 2013) and by 4 weeks in mice [64]. Nonetheless, myelination continues long into adulthood and is important for neural circuit plasticity and
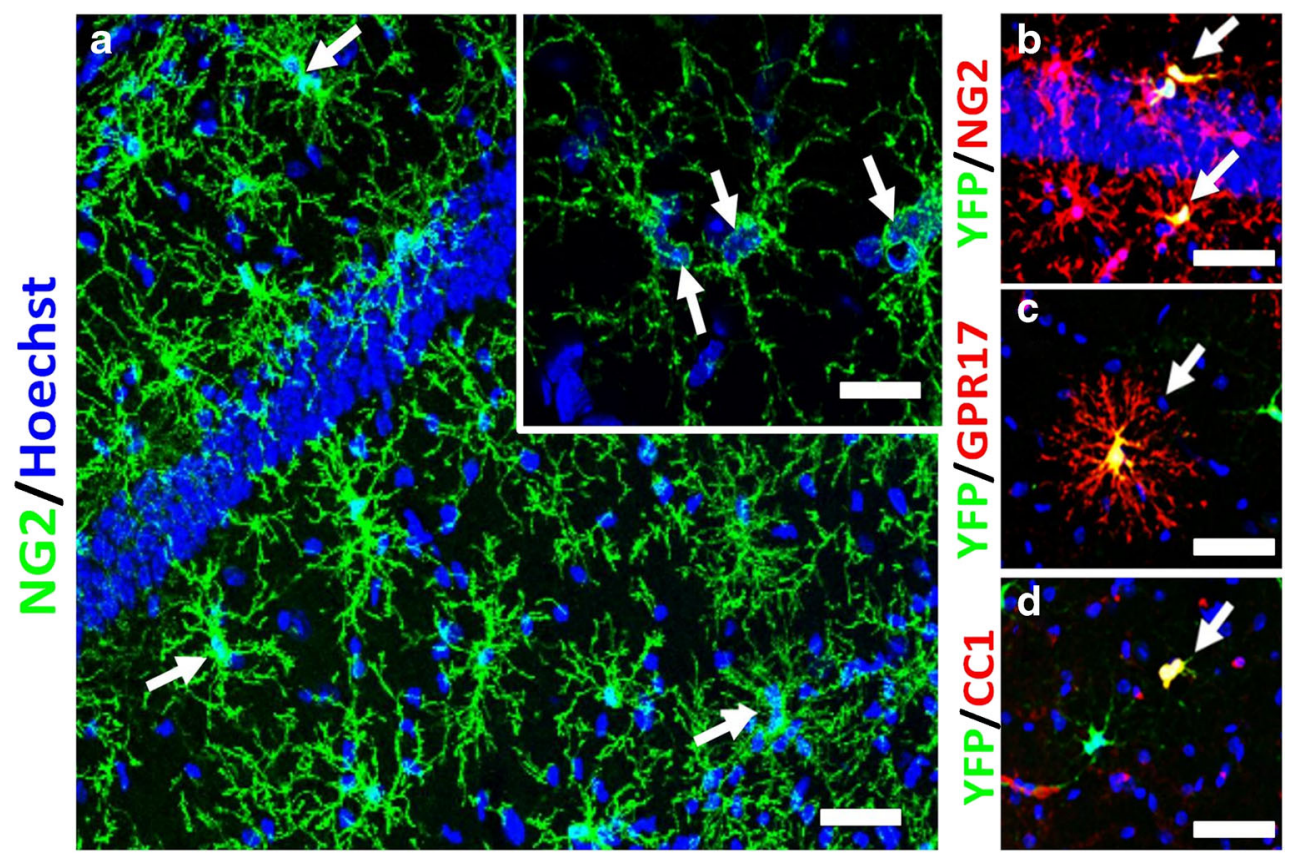

Fig. 2 Adult NG2+/Pdgfra+ OPCs divide to undergo self-renewal and generate a reservoir of GPR17+ differentiation committed OPCs (COPs), which differentiate into $\mathrm{CC} 1+$ mature oligodendrocytes. a OPCs immunolabeled for NG2 in the hippocampus of the adult brain. White arrows show duplets of recently divided sister cells, as illustrated in the inset showing a high magnification confocal image of an OPC duplet. bd Oligodendroglial cells in 3-month-old Pdgfra-CreER ${ }^{\mathrm{T} 2}$ :Rosa26R-YFP mouse, 10 days following tamoxifen injection, immunolabelled for YFP to identify OPCs and their progeny (green, co-expression appears yellow), double immunofluorescence labelled for the OPC marker NG2 (B, red), GPR17 for COPs' (c, red, arrows) and $\mathrm{CC} 1$ for mature oligodendrocytes (d, red, arrows). Scale bars $=50 \mu \mathrm{m}$ in A-D, and $10 \mu \mathrm{m}$ in insets in $\mathbf{a}$ 
cognitive learning in mice and man [66]. Oligodendrocytes are generated throughout adulthood by a significant population of 'adult OPCs', which slowly divide to maintain their own population, termed 'self-renewal', and to generate newly formed oligodendrocytes [79]. A characteristic of OPCs is that they form synapses with neurons and respond to neuronal signalling [7]. Neuronal activity regulates oligodendrogenesis and myelination $[35,38,53]$, which is critical for adaptive changes in learning and cognitive function $[33,69,78]$. Recent studies have determined that cortical OPCs receive extensive afferent synaptic inputs from brain-wide projection networks [54], and neurotransmission regulates both the expansion of OPCs and their differentiation into oligodendrocytes [35]. Synaptic input is important for maintaining OPC numbers [14], and age-related changes in neuronal signalling are intrinsically associated with a decline in OPC regenerative capacity [72] (Fig. 3). In this context, there are prominent roles for purinergic and glutamatergic signalling in regulating OPC proliferation and differentiation, notably via $\mathrm{P} 2 \mathrm{X} 7 \mathrm{R}$, which are the purinergic receptor with the highest expression in OPC [43], and AMPA-type glutamate receptors [15]. Significantly, P2X7R is central to white matter pathology [28], but it is implicit that expression of P2X7R by OPCs must also have a physiological role [10], and there is evidence that P2X7R induce calcium rises in OPCs and regulate their migration, proliferation and differentiation [3, 27]. Moreover, using an NG2-DsRed mouse line to unambiguously identify NG2+ OPCs in the mouse optic nerve, we have demonstrated that OPCs respond to ATP and glutamate released by neuronal activity with increases in intracellular
$\mathrm{Ca}^{2+}$, and showed that P2X7R and AMPAR are major contributors to such OPC functions [37]. Of course, neurotransmitters other than ATP and glutamate also regulate OPCs, including noradrenaline [12], which acts not only as a messenger, but also as a growth factor and as an inhibitor of proinflammatory conditions that are prominent in the aged brain [44]. Hence, reduced noradrenergic innervation in the aged brain due to the demise of the Locus coeruleus [76] may play an important role in OPC decline in ageing WM, either directly or via altered astrocyte function [58]. Furthermore, OPCs sense potassium released during neuronal activity through the potassium channels they express, notably Kir4.1, as well as sensing metabolites, including L-lactate, which represent further modes of OPC signal integration $[12,58]$. Overall, OPC self-renewal is at least partly dependent on neuronal activity and age-related dysregulation of neurotransmission is a potential causative factor in the loss of OPCs and myelin $[13,73]$.

\section{The adult brain contains distinct pools of NG2+ and GPR17+ OPCs that are altered in ageing}

During development, OPCs arise from focal sources to migrate throughout the CNS, where they proliferate and differentiate into oligodendrocytes, under the control of multifarious intrinsic and extrinsic factors [26]. Although adult OPCs are generally treated as a single uniform population, it is evident they are a heterogeneous population and that not all

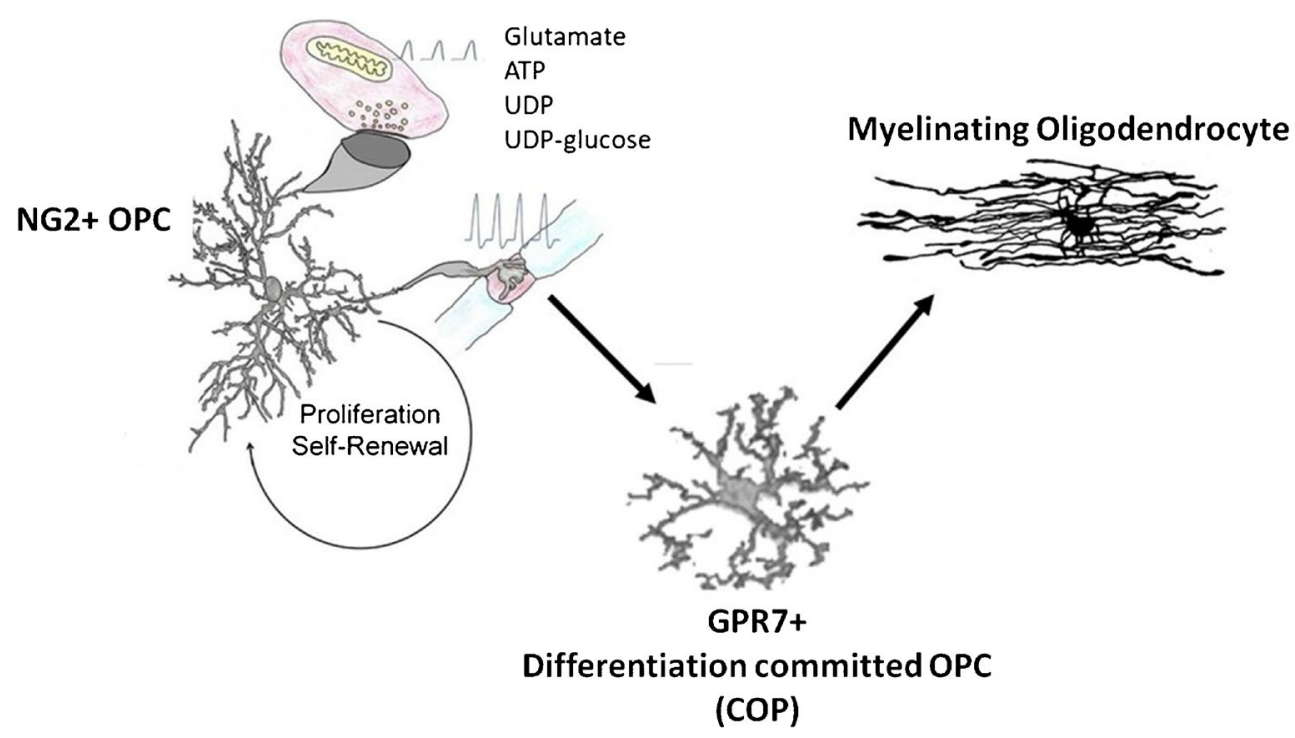

Fig. 3 Two distinct pools of adult OPCs maintain life-long generation of myelinating oligodendrocytes. Slowly dividing NG2+ OPCs are responsible for self-renewal and maintaining a reservoir of GPR17+ COPs that are devoted to rapidly generating myelinating oligodendrocytes. Neuronal signalling involving P2X7R and GPR17, together with

glutamate, noradrenaline and potassium, play an important role in regulating OPC function. There are marked decreases in both NG2+OPCs and GPR $17+$ COPs in the ageing brain, which results in impaired replacement of myelin lost through ageing, and is a key factor in the age-related decline in neuronal network plasticity and cognitive function 
OPCs are directly involved in the generation of myelinating oligodendrocytes [11]. Prior to differentiating into mature myelinating oligodendrocytes, NG2+ OPCs pass through a distinct differentiation phase characterised by expression of the G-protein-coupled receptor subtype GPR17 [30] (Fig. 4). Single-cell RNAseq has identified multiple cell subpopulations belonging to the oligodendrocyte lineage and GPR17 expression was identified in clusters that can be collectively defined as 'differentiation committed OPC' (COPs) [49]. In support of this, analysis of OPC heterogeneity in zebrafish spinal cord revealed that GPR17 is differentially expressed in a subset of OPCs that generate differentiated oligodendrocytes, while it is virtually absent in a subgroup of OPCs that seem to be more involved in synaptic signalling [48]. Adult OPCs can be broadly subdivided into two functionally distinct pools of slowly dividing NG2+ OPCs that have the stem celllike property of self-renewal [12], and GPR17+ COPs, that are normally quiescent and differentiate into myelinating oligodendrocytes when needed $[18,75]$. Thus, the function of NG2+ OPCs is self-renewal and replenishment of GPR17+ COPs, which serve as 'reservoir' of cells devoted to rapidly generating myelinating oligodendrocytes [45]. It is significant, therefore, that we have recently demonstrated a marked decrease in both NG2+OPCs and GPR17+ COPs in the ageing brain [63], caused by reduced self-renewal of OPCs [56], together with their diminished replenishment of the reservoir of GPR17+ COPs [63]. The dysregulation of OPCs and COPs results in impaired replacement of myelin lost through ageing $[56,63]$, which is a key factor in the age-related decline in neuronal network plasticity and cognitive function [6], and for myelin loss in $\mathrm{AD}$ and the failure of remyelination in chronic
MS [55, 67]. Transcriptomic studies are beginning to unravel the signalling pathways and biological processes that are altered in aged OPCs, and notable amongst these are cell metabolism and synaptic signalling [20,63]. Our meta-analysis of the stage-specific transcriptional signatures of ageing cortical OPC identified novel interactions between Gpr17 and Cacng4 (Stargazin) [63], which targets AMPA receptors to the OPC cell membrane [82], to regulate OPC proliferation, differentiation and myelination [15]. Furthermore, P2X7R have also been shown to regulate AMPAR trafficking and enhance glutamatergic synaptic signalling [60]. Transcriptomics evidence has indicated both AMPAR and $\mathrm{P} 2 \mathrm{X} 7 \mathrm{R}$ are disrupted in ageing white matter [72]. Moreover, GPR17 and P2X7R are both important regulators of cellular metabolism [17, 61], which is central to age-related dysregulation of OPCs [56]. Thus, the collective disruption of GPR17 and P2X7R could result in severe disruption of aged OPCs, as both genes are detected at very low expression compared to young OPCs (Fig. 5), in addition to other factors, such as reduced noradrenergic signalling and metabolic support by astrocytes $[58,74,76]$.

\section{Roles for P2X7R and GPR17 in OPC ageing and cellular metabolism}

P2X7R are usually considered cytotoxic receptors, butalso have an important physiological function as sensors of cellular metabolic state and, on activation, can regulate cell metabolism [22]. Furthermore, although it is generally held that P2X7R are activated only at pathologically high

\section{Bulk Sequencing Profiles}

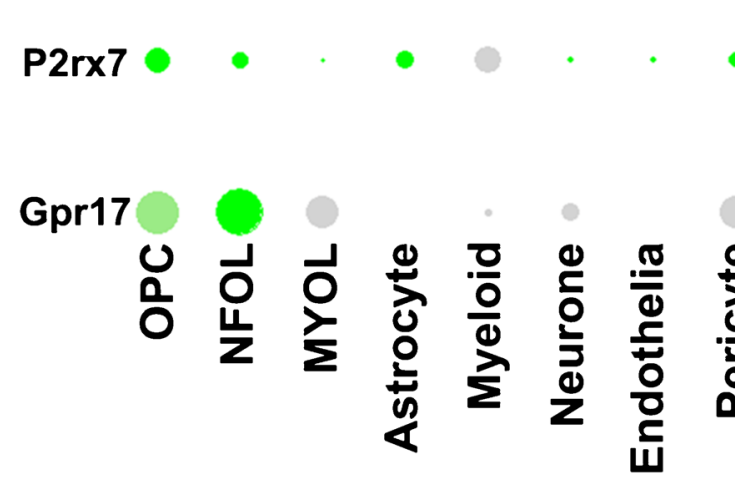

Fig. 4 Specific expression of GPR17 and P2RX7 in mouse oligodendroglial cells. Transcript signals values of mouse brain cells from publically available datasets of bulk sequencing [80] and singlecell sequencing [40] were analysed using the DeSeq2, Seurat and ggplot2 packages in RStudio, following standard published procedures [59, 63].

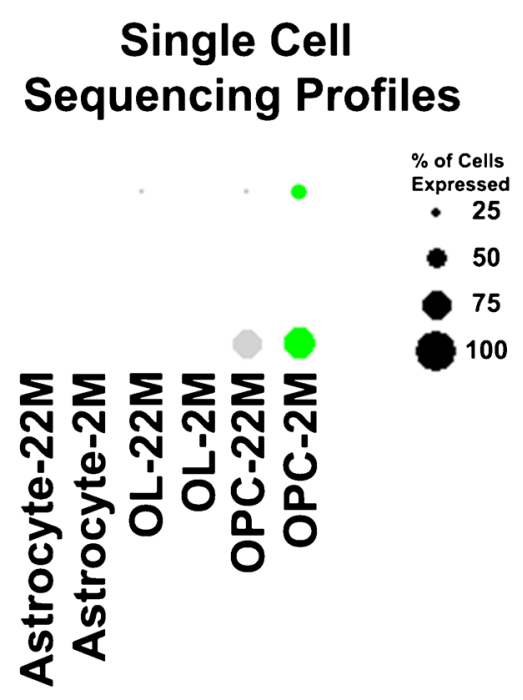

Bulk sequencing profiles indicate highest expression of $P 2 r x 7$ corresponds to Gprl7 in OPCs and COPs, compared to other cells. This was confirmed in single-cell sequencing profiles, which indicate a marked decrease in expression levels of both P2rx 7 and Gpr17 in aged OPCs (22 months of age, $22 \mathrm{M}$ ) compared to adult OPCs ( 2 months of age, $2 \mathrm{M}$ ) 


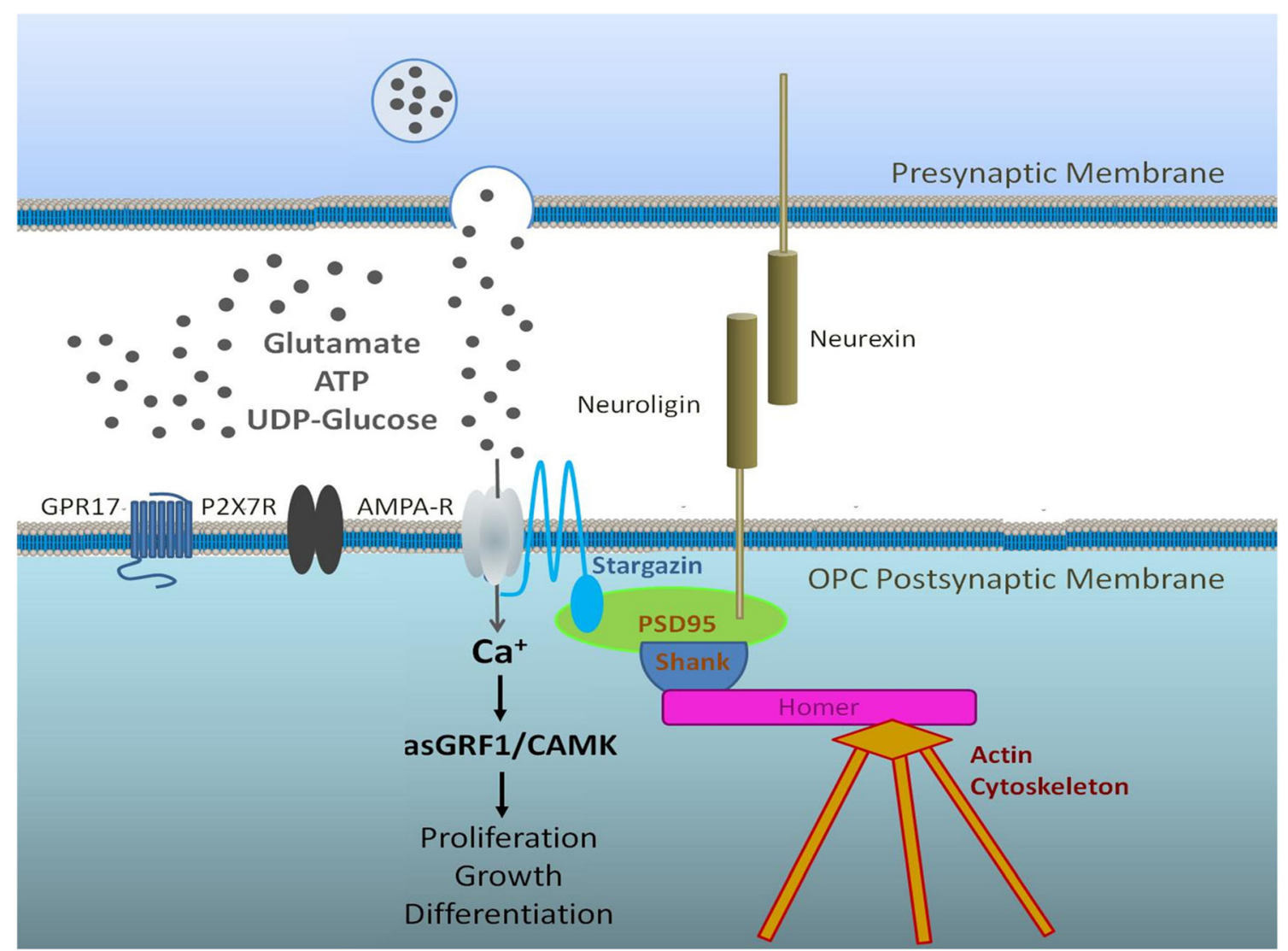

Fig. 5 Prominent roles for purinergic and glutamatergic signalling in regulating OPC proliferation and differentiation.AMPA-type glutamate receptors and P2X7R subtype of ATP receptors are highly expressed by OPCs, which are charecterised by expression of the NG2 CSPG and

concentrations of extracellular ATP, there is evidence that ATP is released physiologically in the CNS during neuronal activity at high enough concentrations to activate P2X7R, as a neurotransmitter in its own right, or as a co-transmitter with glutamate or other neurotransmitters [1]. A recent study measured ATP changes in response to neuronal activity in the cerebral cortex of living mice and demonstrated an ATP wave that propagated at the speed of $\sim 2 \mathrm{~mm} / \mathrm{min}$, comparable to the rate of neuronal propagation, with a precipitous rise of ATP at the wave front that occurred across a broad area of the brain [41]. In addition, we have shown an equivalent rise in ATP in response to neuronal activity that is propagated by ATP release from astrocytes in WM of the mouse optic nerve [36], at elevated levels sufficient to activate P2X7R on OPCs [37]. Furthermore, it is now evident that ATP is continuously released in the brain and extracellular levels are altered in response to metabolic demand $[25,47,51]$, linked to reciprocal changes in the levels of phosphorylated AMP-activated protein kinase (P-AMPK), well known for its role in cellular energy sensing and regulation [25]. Controlled activation ofP2X7R supports mitochondrial ATP synthesis in multiple ways, including facilitating glucose uptake by regulating glucose transporter expression and function [4], and stimulation
GPR17. Potential interactions between GPR17, P2X7R and the targeting of AMPA receptors to the OPC cell membrane are implicated in age-related dysregulation of OPCs

ofP2X7R has been shown to enhance energy metabolism in mice [34]. In addition, circadian regulation of extracellular ATP levels suggests that ATP may be an important circadian output in thesuprachiasmatic nucleus and other brain regions [77]. Similarly, physiological ligands for GPR 17 include UDP and UDP-glucose[16], which are important factors in glycogenesis [29], and may be released from neurons and astrocytes to activate receptors on OPCs [24]. Importantly, oligodendroglial GPR17 has been shown to regulate whole-body metabolism and food intake by modulating hypothalamic neuronal activity $[57,61,70]$. In this context, P2X7R and GPR17 act as bioenergetics sensors and provide mechanisms by which OPCs regulate cellular metabolism and survival. Moreover, evidence that activation of GPR17 by uracil nucleotides is reversed by some purinergic antagonists [30] raises the possibility of interactions between GPR17 and P2X7R. It is significant, therefore, that GPR 17 and $\mathrm{P} 2 \mathrm{X} 7 \mathrm{R}$ regulate whole-body metabolism and are implicated in type- 2 diabetes $[17,61]$ and regulate mTOR and AMPK $[8,62]$, which also contribute to type-2 diabetes [39], since dysregulation of these pathways are central to age-related changes in OPCs and targeting these pathways rejuvenates ageing OPC stemness $[56,63]$. Moreover, activation of P2X7R modulates GSK3 $\beta$ 
and intracellular glycogen stores [23], and we have demonstrated that inhibition of GSK $3 \beta$ profoundly promotes oligodendrogenesis and rejuvenates the regenerative capacity of OPCs [5]. In this respect, it is worth noting that astrocytes are the primary store of glycogen in the brain, which is a source of metabolic support for OPCs [58]. Moreover, activation of GPR17 in OPCs decreases intracellular levels of cAMP [68], which is an important regulator of glycogenolysis, and the decline in excitation-energy coupling is likely to be an important factor in the ageing brain [74].

\section{Oligodendrocytes provide metabolic support for axons}

In addition to myelination, oligodendrocytes provide metabolic support for axons, possibly in the form of glucose [52], but mainly by delivering lactate to axons, which they release through MCT1 into the periaxonal space, from where it is taken up by axons via MCT2 $[31,46]$. Metabolic support is coupled to axonal activity, which stimulates oligodendroglial expression of the glucose transporter GLUT1 and glucose uptake, which is metabolised to lactate and released to axons [65]. The physiological importance of oligodendrocyte-axon metabolic support is critical under conditions of glucose deprivation [71]. Interestingly, downregulation of GPR17 in oligodendroglia enhanced glycolysis and lactate production, which then activated neurons in the hypothalamus [57], suggesting that the loss of GPR17 during the maturation of myelinating oligodendrocytes would increase their capacity for metabolic support of axons. As noted above, oligodendroglial P2X7R are activated by ATP released during neuronal activity $[36,37]$, and extracellular ATP levels increase under metabolic stress [51]. Furthermore, evidence that activation of P2X7R regulates glycolysis and facilitates glucose uptake via increased GLUT1 expression and function [4] provides a physiological function for oligodendroglial P2X7R in supporting axonal metabolism and integrity, as shown for glutamate and NMDAR [65]. Hence, in addition to resulting in dysregulation of OPC cellular metabolism, age-related changes in oligodendroglial P2X7R and GPR17 may have adverse effects on axonal metabolism, in particular under times of metabolic stress, which is a hallmark of brain ageing [50], and is postulated to play a key role in neuronal demise in $\mathrm{AD}$ [19] and MS [2].

\section{Summary and conclusions}

In summary, WM shrinkage and myelin loss in the ageing brain underpin a decline in neuronal plasticity and cognitive function. A key factor in the loss of myelin is the age-related decay in OPC regenerative capacity, which is associated with dysregulation of cellular metobilism. Notably, OPCs express GPR17 and P2X7R, which are key regulators of OPC differentiation and can be considered bioenergetics sensors that regulate cellular metabolism to meet changes in energy demands. Overall, evidence for dysregulation of GPR17 and $\mathrm{P} 2 \mathrm{X} 7 \mathrm{R}$ in ageing supports key roles for these receptors in the age-related loss of OPC stemness and their regeneration of myelinating oligodendrocytes. Furthermore, such changes in P2X7R and GPR17 would have adverse effects on axonal trophic support and is likely to contribute to neurodegenerative changes in ageing WM, both through disruption of their metabolic roles in oligodendroglial glycolysis and their importance in regulating oligodendrocyte regeneration and myelination. Thus, P2X7R and GPR17 are potential therapeutic targets for rejuvenating OPCs and promoting myelin repair and neuroprotection in age-dependent neuropathology, including MS and AD.

Funding The authors were supported by grants from the BBSRC (AB, Grant Number BB/M029379/1), MRC (AB, Grant Number MR/ P025811/1), MS Society of the UK (AB, Award Reference: 40) and MSCA Seal of Excellence @ UNIPD (ADR).

Open Access This article is licensed under a Creative Commons Attribution 4.0 International License, which permits use, sharing, adaptation, distribution and reproduction in any medium or format, as long as you give appropriate credit to the original author(s) and the source, provide a link to the Creative Commons licence, and indicate if changes were made. The images or other third party material in this article are included in the article's Creative Commons licence, unless indicated otherwise in a credit line to the material. If material is not included in the article's Creative Commons licence and your intended use is not permitted by statutory regulation or exceeds the permitted use, you will need to obtain permission directly from the copyright holder. To view a copy of this licence, visit http://creativecommons.org/licenses/by/4.0/.

\section{References}

1. Abbracchio MP, Burnstock G, Verkhratsky A, Zimmermann H (2009) Purinergic signalling in the nervous system: an overview. Trends Neurosci 32:19-29

2. Adiele RC, Adiele CA (2019) Metabolic defects in multiple sclerosis. Mitochondrion 44:7-14

3. Agresti C, Meomartini ME, Amadio S, Ambrosini E, Volonté C, Aloisi F, Visentin S (2005) ATP regulates oligodendrocyte progenitor migration, proliferation, and differentiation: involvement of metabotropic P2 receptors. Brain Res Rev 48:157-165

4. Amoroso F, Falzoni S, Adinolfi E, Ferrari D, Di Virgilio F (2012) The P2X7 receptor is a key modulator of aerobic glycolysis. Cell Death Dis 3:e370

5. Azim K, Angonin D, Marcy G, Pieropan F, Rivera A, Donega V, Cantù C, Williams G, Berninger B, Butt AM, Raineteau O (2017) Pharmacogenomic identification of small molecules for lineage specific manipulation of subventricular zone germinal activity. PLoS Biol 15:e2000698 
6. Bartzokis G (2004) Age-related myelin breakdown: a developmental model of cognitive decline and Alzheimer's disease. Neurobiol Aging 25:5-18; author reply 49-62

7. Bergles DE, Jabs R, Steinhauser C (2010) Neuron-glia synapses in the brain. Brain Res Rev 63:130-137

8. Bian S, Sun X, Bai A, Zhang C, Li L, Enjyoji K, Junger WG, Robson SC, Wu Y (2013) P2X7 integrates PI3K/AKT and AMPK-PRAS40-mTOR signaling pathways to mediate tumor cell death. PLoS One 8:e60184-e60184

9. Butt AM, De La Rocha IC, Rivera A (2019) Oligodendroglial cells in Alzheimer's disease. Adv Exp Med Biol 1175:325-333

10. Butt AM, Fern RF, Matute C (2014) Neurotransmitter signaling in white matter. Glia 62:1762-1779

11. Butt AM, Kiff J, Hubbard P, Berry M (2002) Synantocytes: new functions for novel NG2 expressing glia. J Neurocytol 31:551-565

12. Butt AM, Papanikolaou M, Rivera A (2019) Physiology of oligodendroglia. Adv Exp Med Biol 1175:117-128

13. Chacon-De-La-Rocha I, Fryatt G, Rivera A, Verkhratsky A, Raineteau O, Gomez-Nicola D, Butt AM (2020) Accelerated dystrophy and decay of oligodendrocyte precursor cells in the APP/ PS1 model of Alzheimer's-like pathology. Front Cell Neurosci 14: 575082

14. Chacon-De-La-Rocha I, Fryatt GL, Rivera AD, Restani L, Caleo M, Raineteau O, Gomez-Nicola D, Butt AM (2020) Synaptic silencing affects the density and complexity of oligodendrocyte precursor cells in the adult mouse hippocampus. https://doi.org/10. $1101 / 2020.09 .23 .309682$

15. Chen TJ, Kula B, Nagy B, Barzan R, Gall A, Ehrlich I, Kukley M (2018) In vivo regulation of oligodendrocyte precursor cell proliferation and differentiation by the AMPA-receptor subunit GluA2. Cell Rep 25:852-861.e857

16. Ciana P, Fumagalli M, Trincavelli ML, Verderio C, Rosa P, Lecca D, Ferrario S, Parravicini C, Capra V, Gelosa P, Guerrini U, Belcredito S, Cimino M, Sironi L, Tremoli E, Rovati GE, Martini C, Abbracchio MP (2006) The orphan receptor GPR17 identified as a new dual uracil nucleotides/cysteinyl-leukotrienes receptor. EMBO J 25:4615-4627

17. Coccurello R, Volonté C (2020) P2X7 Receptor in the management of energy homeostasis: implications for obesity, dyslipidemia, and insulin resistance. Front Endocrinol 11:199

18. Coppolino GT, Marangon D, Negri C, Menichetti G, Fumagalli M, Gelosa P, Dimou L, Furlan R, Lecca D, Abbracchio MP (2018) Differential local tissue permissiveness influences the final fate of GPR17-expressing oligodendrocyte precursors in two distinct models of demyelination. Glia 66:1118-1130

19. De Felice FG, Lourenco MV (2015) Brain metabolic stress and neuroinflammation at the basis of cognitive impairment in Alzheimer's disease. Front Aging Neurosci 7:94-94

20. de la Fuente AG, Queiroz RML, Ghosh T, McMurran CE, Cubillos JF, Bergles DE, Fitzgerald DC, Jones CA, Lilley KS, Glover CP, Franklin RJM (2020) Changes in the oligodendrocyte progenitor cell proteome with ageing. Mol Cell Proteomics 19:1281-1302

21. De León Reyes NS, Bragg-Gonzalo L, Nieto M (2020) Development and plasticity of the corpus callosum. Development 147:dev189738

22. Di Virgilio F, Ferrari D, Adinolfi E (2009) P2X(7): a growthpromoting receptor-implications for cancer. Purinergic Signal 5: 251-256

23. Díaz-Hernandéz J, Gomez-Villafuertes R, León-Otegui M, Hontecillas-Prieto L, del Puerto A, Trejo J, Lucas J, Garrido J, Gualix J, Miras-Portugal MT, Diaz-Hernandez M (2011) In vivo P2X7 inhibition reduces amyloid plaques in Alzheimer's disease through GSK3 $\beta$ and secretases. Neurobiol Aging 33:1816-1828

24. Dobolyi A, Juhász G, Kovács Z, Kardos J (2011) Uridine function in the central nervous system. Curr Top Med Chem 11:1058-1067
25. Dworak M, McCarley RW, Kim T, Kalinchuk AV, Basheer R (2010) Sleep and brain energy levels: ATP changes during sleep. J Neurosci 30:9007-9016

26. Elbaz B, Popko B (2019) Molecular control of oligodendrocyte development. Trends Neurosci 42:263-277

27. Feng J-F, Gao X-F, Pu Y-Y, Burnstock G, Xiang Z, He C (2015) $\mathrm{P} 2 \mathrm{X} 7$ receptors and Fyn kinase mediate ATP-induced oligodendrocyte progenitor cell migration. Purinergic Signal 11:361-369

28. Fern RF, Matute C, Stys PK (2014) White matter injury: ischemic and nonischemic. Glia 62:1780-1789

29. Führing JI, Cramer JT, Schneider J, Baruch P, Gerardy-Schahn R, Fedorov R (2015) A Quaternary mechanism enables the complex biological functions of octameric human UDP-glucose pyrophosphorylase, a key enzyme in cell metabolism. Sci Rep 5:9618

30. Fumagalli M, Lecca D, Coppolino GT, Parravicini C, Abbracchio MP (2017) Pharmacological properties and biological functions of the GPR17 receptor, a potential target for neuro-regenerative medicine. Adv Exp Med Biol 1051:169-192

31. Funfschilling U, Supplie LM, Mahad D, Boretius S, Saab AS, Edgar J, Brinkmann BG, Kassmann CM, Tzvetanova ID, Mobius W, Diaz F, Meijer D, Suter U, Hamprecht B, Sereda MW, Moraes CT, Frahm J, Goebbels S, Nave KA (2012) Glycolytic oligodendrocytes maintain myelin and long-term axonal integrity. Nature 485:517-521

32. Gazzaniga MS (2000) Cerebral specialization and interhemispheric communication: does the corpus callosum enable the human condition? Brain 123:1293-1326

33. Geraghty AC, Gibson EM, Ghanem RA, Greene JJ, Ocampo A, Goldstein AK, Ni L, Yang T, Marton RM, Paşca SP, Greenberg ME, Longo FM, Monje M (2019) Loss of adaptive myelination contributes to methotrexate chemotherapy-related cognitive impairment. Neuron 103:250-265.e258

34. Giacovazzo G, Fabbrizio P, Apolloni S, Coccurello R, Volonté C (2019) Stimulation of P2X7 enhances whole body energy metabolism in mice. Front Cell Neurosci 13:390

35. Gibson EM, Purger D, Mount CW, Goldstein AK, Lin GL, Wood LS, Inema I, Miller SE, Bieri G, Zuchero JB, Barres BA, Woo PJ, Vogel H, Monje M (2014) Neuronal activity promotes oligodendrogenesis and adaptive myelination in the mammalian brain. Science 344:1252304

36. Hamilton N, Vayro S, Kirchhoff F, Verkhratsky A, Robbins J, Gorecki DC, Butt AM (2008) Mechanisms of ATP- and glutamate-mediated calcium signaling in white matter astrocytes. Glia 56:734-749

37. Hamilton N, Vayro S, Wigley R, Butt AM (2010) Axons and astrocytes release ATP and glutamate to evoke calcium signals in NG2-glia. Glia 58:66-79

38. Hughes EG, Orthmann-Murphy JL, Langseth AJ, Bergles DE (2018) Myelin remodeling through experience-dependent oligodendrogenesis in the adult somatosensory cortex. Nat Neurosci 21:696-706

39. Inoki K, Kim J, Guan K-L (2012) AMPK and mTOR in cellular energy homeostasis and drug targets. Annu Rev Pharmacol Toxicol 52:381-400

40. Kalamakis G, Brüne D, Ravichandran S, Bolz J, Fan W, Ziebell F, Stiehl T, Catalá-Martinez F, Kupke J, Zhao S, Llorens-Bobadilla E, Bauer K, Limpert S, Berger B, Christen U, Schmezer P, Mallm JP, Berninger B, Anders S, del Sol A, Marciniak-Czochra A, MartinVillalba A (2019) Quiescence modulates stem cell maintenance and regenerative capacity in the aging brain. Cell 176:14071419.e1414

41. Kitajima N, Takikawa K, Sekiya H, Satoh K, Asanuma D, Sakamoto H, Takahashi S, Hanaoka K, Urano Y, Namiki S, Iino M, Hirose K (2020) Real-time in vivo imaging of extracellular ATP in the brain with a hybrid-type fluorescent sensor. Elife 9:e57544 
42. Koshiyama D, Fukunaga M, Okada N, Morita K, Nemoto K, Usui K, Yamamori H, Yasuda Y, Fujimoto M, Kudo N, Azechi H, Watanabe Y, Hashimoto N, Narita H, Kusumi I, Ohi K, Shimada T, Kataoka Y, Yamamoto M, Ozaki N, Okada G, Okamoto Y, Harada K, Matsuo K, Yamasue H, Abe O, Hashimoto R, Takahashi T, Hori T, Nakataki M, Onitsuka T, Holleran L, Jahanshad N, van Erp TGM, Turner J, Donohoe G, Thompson PM, Kasai K, Hashimoto R, Cocoro (2020) White matter microstructural alterations across four major psychiatric disorders: megaanalysis study in 2937 individuals. Mol Psychiatry 25:883-895

43. Larson VA, Zhang Y, Bergles DE (2016) Electrophysiological properties of $\mathrm{NG} 2(+)$ cells: matching physiological studies with gene expression profiles. Brain Res 1638:138-160

44. Leanza G, Gulino R, Zorec R (2018) Noradrenergic hypothesis linking neurodegeneration-based cognitive decline and astroglia. Front Mol Neurosci 11:254

45. Lecca D, Raffaele S, Abbracchio MP, Fumagalli M (2020) Regulation and signaling of the GPR17 receptor in oligodendroglial cells. Glia 68:1957-1967

46. Lee Y, Morrison BM, Li Y, Lengacher S, Farah MH, Hoffman PN, Liu Y, Tsingalia A, Jin L, Zhang PW, Pellerin L, Magistretti PJ, Rothstein JD (2012) Oligodendroglia metabolically support axons and contribute to neurodegeneration. Nature 487:443-448

47. MacLean DB, Luo LG (2004) Increased ATP content/production in the hypothalamus may be a signal for energy-sensing of satiety: studies of the anorectic mechanism of a plant steroidal glycoside. Brain Res 1020:1-11

48. Marisca R, Hoche T, Agirre E, Hoodless LJ, Barkey W, Auer F, Castelo-Branco G, Czopka T (2020) Functionally distinct subgroups of oligodendrocyte precursor cells integrate neural activity and execute myelin formation. Nat Neurosci 23:363-374

49. Marques S, Zeisel A, Codeluppi S, van Bruggen D, Mendanha Falcão A, Xiao L, Li H, Häring M, Hochgerner H, Romanov RA, Gyllborg D, Muñoz-Manchado AB, La Manno G, Lönnerberg P, Floriddia EM, Rezayee F, Ernfors P, Arenas E, Hjerling-Leffler J, Harkany T, Richardson WD, Linnarsson S, Castelo-Branco G (2016) Oligodendrocyte heterogeneity in the mouse juvenile and adult central nervous system. Science 352:1326-1329

50. Mattson MP, Arumugam TV (2018) Hallmarks of brain aging: adaptive and pathological modification by metabolic states. Cell Metab 27:1176-1199

51. Melani A, Turchi D, Vannucchi MG, Cipriani S, Gianfriddo M, Pedata F (2005) ATP extracellular concentrations are increased in the rat striatum during in vivo ischemia. Neurochem Int 47:442 448

52. Meyer N, Richter N, Fan Z, Siemonsmeier G, Pivneva T, Jordan P, Steinhauser C, Semtner M, Nolte C, Kettenmann H (2018) Oligodendrocytes in the mouse corpus callosum maintain axonal function by delivery of glucose. Cell Rep 22:2383-2394

53. Mitew S, Gobius I, Fenlon LR, McDougall SJ, Hawkes D, Xing YL, Bujalka H, Gundlach AL, Richards LJ, Kilpatrick TJ, Merson TD, Emery B (2018) Pharmacogenetic stimulation of neuronal activity increases myelination in an axon-specific manner. Nat Commun 9:306

54. Mount CW, Yalçın B, Cunliffe-Koehler K, Sundaresh S, Monje M (2019) Monosynaptic tracing maps brain-wide afferent oligodendrocyte precursor cell connectivity. Elife 8:e49291

55. Nasrabady SE, Rizvi B, Goldman JE, Brickman AM (2018) White matter changes in Alzheimer's disease: a focus on myelin and oligodendrocytes. Acta Neuropathol Commun 6:22-22

56. Neumann B, Baror R, Zhao C, Segel M, Dietmann S, Rawji KS, Foerster S, McClain CR, Chalut K, van Wijngaarden P, Franklin RJ (2019) Metformin restores CNS remyelination capacity by rejuvenating aged stem cells. In: Cell Stem Cell: 473-485 e478

57. Ou Z, Ma Y, Sun Y, Zheng G, Wang S, Xing R, Chen X, Han Y, Wang J, Lu QR, Zhao T-J, Chen Y (2019) A GPR17-cAMP-lactate signaling axis in oligodendrocytes regulates whole-body metabolism. Cell Rep 26:2984-2997.e2984

58. Papanikolaou M, Morgan BA (2017) Chapter 3 - White matter astrocytes: adrenergic mechanisms. In: Vardjan N, Zorec R (eds) Noradrenergic Signaling and Astroglia. Academic Press, pp 63-79

59. Pieropan F, Rivera AD, Williams G, Calzolari F, Butt AM, Azim K (2020) Drug connectivity mapping and functional analysis reveals therapeutic small molecules that differentially modulate myelination. bioRxiv 2020.2009.2005.284372

60. Pougnet J-T, Toulme E, Martinez A, Choquet D, Hosy E, BouéGrabot E (2014) ATP P2X receptors downregulate AMPA receptor trafficking and postsynaptic efficacy in hippocampal neurons. Neuron 83:417-430

61. Ren H, Cook JR, Kon N, Accili D (2015) Gpr17 in AgRP neurons regulates feeding and sensitivity to insulin and leptin. Diabetes 64 : 3670-3679

62. Ren H, Orozco Ian J, Su Y, Suyama S, Gutiérrez-Juárez R, Horvath Tamas L, Wardlaw Sharon L, Plum L, Arancio O, Accili D (2012) FoxO1 target Gpr17 activates AgRP neurons to regulate food intake. Cell 149:1314-1326

63. Rivera AD, Pieropan F, De La Rocha IC, Lecca D, Abbracchio MP, Azim K, Butt AM (2020) Functional genomic analyses highlights a shift in Gpr17-regulated cellular processes in oligodendrocyte progenitor cells (OPC) and underlying myelin dysregulation in the aged forebrain. Aging Cell, early view e13335.

64. Rivers LE, Young KM, Rizzi M, Jamen F, Psachoulia K, Wade A, Kessaris N, Richardson WD (2008) PDGFRA/NG2 glia generate myelinating oligodendrocytes and piriform projection neurons in adult mice. Nat Neurosci 11:1392-1401

65. Saab AS, Tzvetavona ID, Trevisiol A, Baltan S, Dibaj P, Kusch K, Mobius W, Goetze B, Jahn HM, Huang W, Steffens H, Schomburg ED, Perez-Samartin A, Perez-Cerda F, Bakhtiari D, Matute C, Lowel S, Griesinger C, Hirrlinger J, Kirchhoff F, Nave KA (2016) Oligodendroglial NMDA receptors regulate glucose import and axonal energy metabolism. Neuron 91:119-132

66. Sampaio-Baptista C, Johansen-Berg H (2017) White matter plasticity in the adult brain. Neuron 96:1239-1251

67. Sanai SA, Saini V, Benedict RHB, Zivadinov R, Teter BE, Ramanathan M, Weinstock-Guttman B (2016) Aging and multiple sclerosis. Mult Scler J 22:717-725

68. Simon K, Hennen S, Merten N, Blättermann S, Gillard M, Kostenis E, Gomeza J (2016) The orphan G protein-coupled receptor GPR17 negatively regulates oligodendrocyte differentiation via $\mathrm{G} \alpha \mathrm{i} / \mathrm{o}$ and its downstream effector molecules. J Biol Chem 291:705-718

69. Steadman PE, Xia F, Ahmed M, Mocle AJ, Penning ARA, Geraghty AC, Steenland HW, Monje M, Josselyn SA, Frankland PW (2020) Disruption of oligodendrogenesis impairs memory consolidation in adult mice. Neuron 105:150-164.e156

70. Steculorum Sophie M, Paeger L, Bremser S, Evers N, Hinze Y, Idzko M, Kloppenburg P, Brüning JC (2015) Hypothalamic UDP increases in obesity and promotes feeding via P2Y6-dependent activation of AgRP neurons. Cell 162:1404-1417

71. Trevisiol A, Saab AS, Winkler U, Marx G, Imamura H, Mobius W, Kusch K, Nave KA, Hirrlinger J (2017) Monitoring ATP dynamics in electrically active white matter tracts. eLife 6:e24241

72. Vanzuli I, Rivera A, Arellano JJ, Butt A (2015) Decreased regenerative capacity of oligodendrocyte progenitor cells (NG2-glia) in the ageing brain: a vicious cycle of synaptic dysfunction, myelin loss and neuronal disruption? Curr Alzheimer Res 13:413-418

73. Vanzulli I, Papanikolaou M, De-La-Rocha IC, Pieropan F, Rivera AD, Gomez-Nicola D, Verkhratsky A, Rodríguez JJ, Butt AM (2020) Disruption of oligodendrocyte progenitor cells is an early sign of pathology in the triple transgenic mouse model of Alzheimer's disease. Neurobiol Aging 94:130-139 
74. Vardjan N, Verkhratsky A, Zorec R (2017) Astrocytic pathological calcium homeostasis and impaired vesicle trafficking in neurodegeneration. Int J Mol Sci 18:356

75. Viganò F, Schneider S, Cimino M, Bonfanti E, Gelosa P, Sironi L, Abbracchio MP, Dimou L (2016) GPR17 expressing NG2-Glia: oligodendrocyte progenitors serving as a reserve pool after injury. Glia 64:287-299

76. Wilson RS, Nag S, Boyle PA, Hizel LP, Yu L, Buchman AS, Schneider JA, Bennett DA (2013) Neural reserve, neuronal density in the locus ceruleus, and cognitive decline. Neurology 80:12021208

77. Womac AD, Burkeen JF, Neuendorff N, Earnest DJ, Zoran MJ (2009) Circadian rhythms of extracellular ATP accumulation in suprachiasmatic nucleus cells and cultured astrocytes. Eur J Neurosci 30:869-876

78. Xiao L, Ohayon D, McKenzie IA, Sinclair-Wilson A, Wright JL, Fudge AD, Emery B, Li H, Richardson WD (2016) Rapid production of new oligodendrocytes is required in the earliest stages of motor-skill learning. Nat Neurosci 19:1210-1217
79. Young KM, Psachoulia K, Tripathi RB, Dunn S-J, Cossell L, Attwell D, Tohyama K, Richardson WD (2013) Oligodendrocyte dynamics in the healthy adult CNS: evidence for myelin remodeling. Neuron 77:873-885

80. Zhang Y, Chen K, Sloan SA, Bennett ML, Scholze AR, O'Keeffe S, Phatnani HP, Guarnieri P, Caneda C, Ruderisch N, Deng S, Liddelow SA, Zhang C, Daneman R, Maniatis T, Barres BA, Wu JQ (2014) An RNA-sequencing transcriptome and splicing database of glia, neurons, and vascular cells of the cerebral cortex. J Neurosci 34:11929-11947

81. Zhu X, Bergles DE, Nishiyama A (2008) NG2 cells generate both oligodendrocytes and gray matter astrocytes. Development 135:145

82. Zonouzi M, Renzi M, Farrant M, Cull-Candy SG (2011) Bidirectional plasticity of calcium-permeable AMPA receptors in oligodendrocyte lineage cells. Nat Neurosci 14:1430-1438

Publisher's note Springer Nature remains neutral with regard to jurisdictional claims in published maps and institutional affiliations. 